gestão tecnológica

1. Introdução;

2. Conceituação de apreciaçẫo tecnológica;

3. Uma visão rápida da apreciação tecnológica;

4. Grandes problemas da apreciação tecnológica.

\section{Uma experiência brasileira de apreciação tecnológica*}

\author{
Ruy Aguiar da Silva Leme \\ Da FEA/USP
}

\section{INTRODUÇÃO}

O progresso tecnológico, no passado sempre considerado benéfico, desde a bomba atômica passou a ser questionado. Recentemente, projetos - com o avião supersônico de transporte de passageiros e o oleoduto do Alasca foram abandonados, alterados ou atrasados por seus efeitos indesejáveis e surgiu uma nova disciplina, a apreciação tecnológica (AT) destinada a analisar os efeitos na sociedade da introdução de uma nova tecnologia. 0 presente trabalho relata a nossa experiência, participando da elaboração de uma apreciação tecnológica do Proálcool. Não serão apresentados os resultados desta apreciação tecnológica, já publicados (Silva Leme, 1980; MIC 1981), limitando-nos a expor os problemas surgidos na sua elaboração, principalmente os devidos às peculiaridades brasileiras.

\section{CONCEITUAÇÃO DE APRECIAÇÃO TECNOLOGICA}

Sendo a apreciação ainda uma novidade no Brasil, convém dedicarmos alguns parágrafos para sua conceituação, Discutiremos, sucessivamente, o sentido de cada uma das duas palavras - "apreciação" e "tecnologia" - tal como são usadas na disciplina e, em seguida, definiremos e comentaremos o que seja uma apreciação tecnológica.

Antes, contudo, desejamos introduzir um neologismo cujo emprego é indispensável nas apreciaçōes tecnológicas. Trata-se de "societal" e diz respeito à sociedade.
Problemas societais são poblemas da sociedade, sejam econômicos, políticos, institucionais, tecnologicos, ambientais ou sociais, contrapondo-se aos problemas sociais muito mais restritos, pois excluem os das outras categorias.

Iniciando pela palavra "apreciação", desejamos comentar que foi esta a melhor tradução por nós encontrada para a expressão da língua inglesa assessmet. Em seu sentido literal, na lingua inglesa, como define o Webster's New International Dictionary (Neilson et alii, 1939), significa fixação de valores para efeito de impostos, vindo do latim assessare, que significa avaliar para taxação. Distingue-se de valuation, evaluation, appraisal, appreciation, que significam fixação de preço, de valor de mercado. A rigor, valuation e evaluation seriam traduzidos no português por valoração e avaliação, enquanto appraisal (ad praise; price) e appreciation por apreciação, não havendo boa tradução para assessmet. Alguns têm traduzido technological assessment, por avaliação tecnológica, mas pessoalmente não gostamos desta tradução, pois poderia ser entendida como fixação do valor da tecnologia, o que náo é o objeto da AT. Na AT apreciamos a tecnologia no sentido de examinar seus impactos sobre a sociedade, distinguindo os bons dos maus e medindo sua intensidade.

Passando para a palavra "tecnologia", encontramos uma das expressões de mais difícil conceituação. Recentemente, Almeida (1981) discutiu várias definições. Em nosso caso particular, podemos dizer que nas AT, tecnologia significa a aplicação da ciência e da arte para atingir os fins do homem. $O$ objeto de uma AT pode ser uma tecnologia física, tecnológica ou social. As duas primeiras são as mais lembradas, mas a última também existe, e tem sido objeto de AT, como a semana de quatro dias de trabalho. Por outro lado, o objeto de uma AT pode ser uma tecnologia - por exemplo, o uso do álcool nos motores diesel - ou um problema e as tecnologias capazes de resolvê-lo - por exemplo, substitutos dos derivados de petroleo nos motores diesel - ou ainda um projeto ou programa, onde temos o uso de uma dada tecnologia resolvendo um certo problema, numa dada situação, como, por exemplo, o Proálcool. Juntando estas duas dimensỗes, temos os seguintes objetos para uma AT:

Quadro 1

Objetos de uma apreciação tecnológica

\begin{tabular}{llll}
\hline & \multicolumn{3}{c}{ Orientação da AT. } \\
\cline { 2 - 4 } $\begin{array}{l}\text { Tipo de } \\
\text { tecnologia }\end{array}$ & $\begin{array}{l}\text { Orientada por } \\
\text { tecnologia }\end{array}$ & $\begin{array}{l}\text { Orientada por } \\
\text { problema }\end{array}$ & $\begin{array}{l}\text { Orientada por } \\
\text { projeto }\end{array}$ \\
\hline Física & $\begin{array}{l}\text { Uso do álcool } \\
\text { nos motores } \\
\text { diesel }\end{array}$ & $\begin{array}{l}\text { Substituição } \\
\text { do petróleo } \\
\text { nos motores } \\
\text { diesel }\end{array}$ & Proálcool \\
Biológica & $\begin{array}{l}\text { Diagnóstico } \\
\text { precoce }\end{array}$ & $\begin{array}{l}\text { Prevenção } \\
\text { do câncer }\end{array}$ & $\begin{array}{l}\text { Programa } \\
\text { de prevenção } \\
\text { do câncer } \\
\text { por diagnóstico } \\
\text { precoce no ano } \\
\text { t, cidade } c\end{array}$ \\
Social & Zonas francas & $\begin{array}{l}\text { Desenvolvimento } \\
\text { da Amazônia }\end{array}$ & $\begin{array}{l}\text { Porto livre } \\
\text { de Manaus }\end{array}$ \\
\hline
\end{tabular}


Comentadas as duas expressð̃es apreciação e tecnologia, passemos a dar algumas definiçōes de AT. "É o estudo sistemático dos efeitos na sociedade que podem ocorrer quando uma tecnologia é introduzida, estelıdida ou modificada, com especial ênfase nos impactos nãointencionais, indiretos ou defasados" (Coates, 1974). "É uma classe de estudos de políticas, dirigidos para examinar as implicaçōes sociais mais amplas da introdução de uma nova tecnologia, da expansão ou extensão de uma tecnologia existente. Pretende fornecer ao toma: dor de decisões conselhos e guias úteis em políticas, programas, planos e ações alternativas" (Coates, 1975).

Alguns comentários auxiliam a elucidar essas definições. Em primeiro lugar, a tecnologia nas duas definições corresponde àquela nas AT orientadas por tecnologia, àquela capaz de resolver o problema, nas AT orientadas por problema, e à tecnologia incorporada no projeto, nas AT orientadas por projeto.

Em segundo lugar, é possivel distinguirem-se os efeitos intencionais, diretos e imediatos, das tecnologias, dos não-intencionais, indiretos e defasados. No Proálcool, por exemplo, os primeiros incluem a economia de divisas e de petróleo; os últimos, mudanças na estrutura fundiária, deslocamento das culturas alimentares etc. Dos primeiros, as AT não precisam cuidar, pois são o próprio objetivo da introdução da tecnologia ou a execução do Programa. Os últimos constituem a preocupação da AT. É válida uma analogia com a medicina. Os remédios têm efeitos principais, diretos $\mathrm{e}$ intencionais, mas também têm efeitos colaterias, nem sempre desejados ou esperados. A AT preocupa-se com os efeitos colaterais da tecnologia. Estes podem ser sumamente importantes para serem negligenciados - como nos detergentes, produzidos para limpar roupas, mas tornando os rios inabitáveis para peixes; no DDT, destinado a combater insetos, mas banido por acumuiar-se em cadeias de alimentos; no automóvel, criado como meio de transporte, mas modificando os padrões de relacionamento entre os sexos.

Em terceiro lugar, a AT é uma disciplina orientada para a ação, para a geração e para a análise de políticas ou decisões. A limitação de espaço não permite que nos alonguemos mais sobre a conceituação da AT. Acrescentaremos, apenas, que é mais uma tecnologia do que uma ciência e não coincide com - se bem que pode incluir a análise custo benefício e estudos de viabilidade econômica, familiares ao economista. Ainda: não é algo novo, pois de alguma forma sempre se fez AT. A novidade está em proceder-se de uma forma sistemática e disciplina.

Finalmente, a AT traduz apenas uma atitude prudente: "Olhe, ante de pular" - isto é, antes de introduzir uma tecnologia ou executar um programa, examine e aprecie seus impactos. Esta talves seja a primeira peculiaridade das AT feitas no Brasil. Nos EUA, um programa como o Proálcool teria sido objeto de uma AT, antes de sua in troduçáo, e o resultado da AT seria muito importante na decisão de se levar adiante ou não o programa. No Brasil, as AT do Proálcool foram realizadas quando este programa já era uma realidade irreversível. Sem dúvida alguma, esta peculiaridade reduz parte do valor da AT, mas não todo. Identificados os impactos negativos e os positivos, cabe à AT recomendar altera- ções na tecnologia que realcem os primeiros e minimizem os últimos.

\section{UMA VISÃO RÁPIDA DA APRECIAÇÃO TECNOLÓGICA}

Antes de en trarmos nos grandes problemas da AT, que constituem o próprio objetivo deste trabalho, é necessário apresentar, resumidamente, qual a seqüência de fases de uma AT.

Não exịste uma metodologia padronizada de AT. Em cada caso tem-se que adaptar o método ao problema em foco. Contudo, deixando detalhes de lado, pode-se reconhecer nos estudos de AT a seqüencia de fases e dẹ interconexões representadas da figura 1.

Figura 1

Fases de uma apreciação tecnologica e suas interrelaçōes

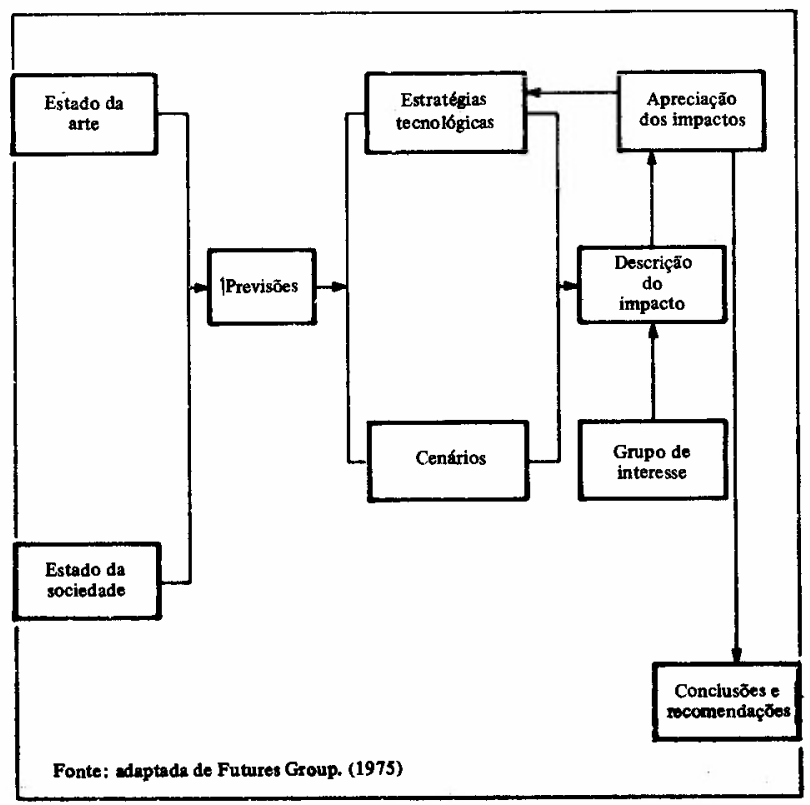

A Al inicia pelo exame do estudo da arte em que é levantado o que se sabe sobre a tecnologia em estudo (ou sobre as tecnologias capazes de resolver o problema, nas AT orientadas por problemas), com ênfase especial nos coeficientes técnicos, isto é, nas quantidades de insumos por unidade de produto. Estes devem ser investigados

Quadro 2

Extrato do estado das artes da AT do Proálcool

\begin{tabular}{lcr}
\hline & $\begin{array}{c}\text { Coeficientes } \\
\text { Presentes }\end{array}$ & $\begin{array}{r}\text { técnicos } \\
\text { Futuros }\end{array}$ \\
\hline Produção agrícola & 65 & 80 \\
$\quad$ Produtividade (T/ha ano) & 150 & 170 \\
$\quad$ Conteúdo de açúcar (kg/T) & & \\
Processamento industrial & 65,0 & 90,0 \\
$\quad$ Rendimento litros/ton & 200 & 300 \\
$\quad$ No de dias de operação/ano & 120.000 & 180.000 \\
$\quad$ Produção de álcool litros/dia & 4.225 & 7.200 \\
\hline Rendimento global L/ha ano & & \\
\hline
\end{tabular}

Fonte de dados brutos: Silva Leme (1980). 
nas condiçరes vigentes na prática, não sendo suficientes os coeficientes correspondentes à eficiência ótima. Um bom exame do estado da arte é imprescindivel para fazer as previsões tecnológicas necessárias para se chegar aos coeficientes técnicos futuros. No quadro 2 tem-se um extrato do estado da arte da AT, do Proálcool.

Na segunda fase da AT, exame do estado da sociedade, são levantados os aspectos societais: sociais, político-institucionais, econômicos e ecológicos, relevantes para o exame dos impactos da(s) tecnologia(s). Para os indicadores societais quantificáveis - por exemplo, produto nacional, população - deve-se levantar uma série tão longa quanto o prazo da previsão. No caso de AT de tecnologias de efeitos restritos, esta fase é dispensável, como se pode verificar em muitos estudos feitos nos EUA. Tornou-se indispensável, no caso do Proálcool, dada a abrangência deste programa na vida nacional. No quadro 3, tem-se um extrato do estado da sociedade da AT do Proálcool.

Quadro 3

Extrato do estado da sociedade da AT do Proálcool

\begin{tabular}{lll}
\hline & \multicolumn{1}{c}{ Valor presente } & \multicolumn{1}{c}{ Previsão } \\
\hline $\begin{array}{l}\text { População } \\
\text { Valor } \\
\text { Taxa de cres- } \\
\text { cimento }\end{array}$ & 113,5 milhões (1977) & 195 milhões (2000) \\
$\begin{array}{l}\text { Percen- } \\
\text { tagem urbana }\end{array}$ & $2,9 \%(1960-77)$ & $2,35 \%(1977.2000)$ \\
$\begin{array}{l}\text { Produto Nacio- } \\
\text { nal Bruto } \\
\text { Taxa de cres- } \\
\text { cimento }\end{array}$ & $6,7 \%(1970)$ & $70 \%(2000)$ \\
$\begin{array}{l}\text { Distribuição } \\
\text { da renda } \\
50 \% \text { mais }\end{array}$ & $11,8 \%(1976)$ & $16 \%(2000)$ \\
$\begin{array}{l}\text { pobres } \\
5 \% \text { mais } \\
\text { ricos }\end{array}$ & $39 \%(1976)$ & $27 \%(2000)$ \\
\hline
\end{tabular}

$\mathrm{Na}$ terceira fase da AT, a de previsão, sáo geradas uma imagem ou conjuntos de imagens do futuro da tecnologia e do estado da sociedade. Como irá evoluir a tecnologia? Estará sujeita a modificações mais profundas? No caso de resposta afirmativa, quando ocorrerão? As mesmas indagaçōes devem ser feitas sobre o estado da sociedade. A previsão deve cobrir pelo menos 20 anos, prazo mínimo para que todos os impactos de tecnologia na sociedade sejam sentidos e para que possam ter efeitos, mudanças na tecnologia. Neste prazo são inaplicáveis métodos como os econométricos, apropriados para prazos de até 10 anos, sendo muito aplicada a técnica Delphi ${ }^{1}$, principalmente nos aspectos quantificáveis (Bright, 1972) ou a Trend Impact Analysis (Futures Group), usada quanto há uma série passada de dados. ${ }^{2}$ Confrontando os dados presentes como os futuros, nos quadros 2 e 3 , tem-se previsóes da tecnologia e do estado da sociedade.

$\mathrm{Na}$ quarta fase, das estratégias tecnológicas, examinam-se as variantes atuais e futuras previstas para a tecnologia, incluindo variantes que decorrem da tentativa de eliminação de impactos negativos, levantados na oitava fase da apreciação. No quadro 4 estão algumas das estratégias tecnológicas examinadas na AT do Proálcool.

$\mathrm{Na}$ quinta fase, as previsðes são grupadas em conjuntos autoconsistentes, descrevendo futuros alternativos,
Quadro 4

Exemplos de estratégias tecnologicas da AT do Proálcool

\begin{tabular}{lccc}
\hline \multirow{2}{*}{$\begin{array}{l}\text { Estratégia } \\
\text { tecnológica }\end{array}$} & \multicolumn{3}{c}{ Produtividade } \\
\cline { 2 - 4 } & $\begin{array}{c}\text { Agrícola } \\
\text { T/ha ano }\end{array}$ & $\begin{array}{c}\text { Industrial } \\
\text { Litros/ton }\end{array}$ & $\begin{array}{c}\text { Global } \\
\text { L/ha ano }\end{array}$ \\
\hline Cana & 80 & 90 & 7.200 \\
Mandioca & 17,5 & 180 & 3.150 \\
Sorgo & 90 & 80 & 7.200 \\
Madeira & 15 & 125 & 1.815 \\
\hline
\end{tabular}

Fonte de dados brutos: Silva Leme (1980).

designados cenários. Como as previsões são sujeitas a uma grande margem de erro, não basta um único cenário, resultante da previsão mais provável. Como, entretanto, são inúmeros os cenários possíveis e relativamente prováveis, e como o número de cenários a serem considerados não pode ser grande, de acordo com a experiência, inferior a oito, um dos problemas delicados da AT é a escolha dos cenários. No quadro 5 estáo resumidos cenários de transporte no Brasil no ano 2000.

Quadro 5

Extratos de cenários de transportes da AT do Proácool

\begin{tabular}{|c|c|c|c|}
\hline & \multirow{2}{*}{$\begin{array}{c}\text { Situação } \\
\text { corrente } \\
\text { (1979) }\end{array}$} & \multicolumn{2}{|c|}{$\begin{array}{l}\text { Cenários } \\
\text { ano } 2000\end{array}$} \\
\hline & & $A$ & $\boldsymbol{B}$ \\
\hline \multicolumn{4}{|l|}{ Transporte de carga } \\
\hline Rodovia & $72 \%$ & $55 \%$ & $45 \%$ \\
\hline Ferrovia & $17 \%$ & $25 \%$ & $35 \%$ \\
\hline Hidrovia & $9 \%$ & $12 \%$ & $12 \%$ \\
\hline Outros & $2 \%$ & $8 \%$ & $8 \%$ \\
\hline \multicolumn{4}{|l|}{ Transporte de passageiro } \\
\hline № de automóveis (milhões) & 8 & 24 & 19 \\
\hline No de ônibus (milhares) & 110 & 350 & 500 \\
\hline Transporte urbano coletivo & $60 \%$ & $67 \%$ & $75 \%$ \\
\hline \multicolumn{4}{|l|}{ Eletrificaçāo do transporte } \\
\hline Ferrovias & $1 \%$ & $6 \%$ & $33 \%$ \\
\hline Onibus urbano & $0,5 \%$ & $3 \%$ & $33 \%$ \\
\hline \multicolumn{4}{|l|}{ Consumo de combustível } \\
\hline Ciclo Otto G + E & 16,9 & 44,1 & 31,5 \\
\hline Ciclo Diesel G+D+E/1.6 & 17,6 & 56,1 & 50,4 \\
\hline
\end{tabular}

Fonte de dados brutos: Silva Leme (1980).

Obs.: G, E, D são as quantidades necessárias de gasolina, etanol e óleo diesel em bilhōes de litros.

Na sexta fase procurase identificar os grupos que provavelmente serão efetuados pela tecnologia: produtores, consumidores, trabalhadores, fabricantes de equipamentos, proprietários rurais, membros da comunidade local etc., designados por grupos de interesse.

Na sétima fase, dadas as estratégias tecnológicas consideradas (fase 4), os cenários alternativos (fase 5) e os grupos de interesse, identificam-se os impactos da tecnologia. Existe uma fase de recrutamento dos impactos, em que se procura relacionar o maior número de impactos, e uma fase de seleçáo dos impactos em que se procura separar os impactos significativos. Na primeira fase, convém considerar altemativamente varios criterios de classificaç̧̃o dos impactos, para que nenhum impacto importante seja esquecido. Assim, deve classificar por disciplinas (sociais, político-institucionais, econômicos, 
ecológicos, tecnológicos), por grandes problemas nacionais (distribuição de renda, inflação, endividamento externo, emprego) e por abrangência (nacionais, regionais, locais). Ainda devem-se considerar impactos comuns às diversas estratégias tecnológicas e os dependentes da estratégia escolhida. Na seleção, partindo-se de uma centena de impactos, por uma apreciação rápida reduz-se a algumas dezenas, deixando de lado impactos de baixa probabilidade ou baixa intensidade. No quadro 6 temos uma relaçáo de impactos que foram considerados na AT do Proálcool.

Quadro 6

Extrato da apreciação de impactos na AT do Proálcool

\begin{tabular}{|c|c|c|c|c|}
\hline Impactos & Cana & Mandioca & Sorgo & Madeira \\
\hline \multicolumn{5}{|l|}{ Ecológicos } \\
\hline Erosão & -1 & -3 & -5 & 0 \\
\hline Defensivos químicos & -1 & -5 & -4 & $\mathbf{0}$ \\
\hline Resíduos químicos & -1 & -1 & -1 & -5 \\
\hline \multicolumn{5}{|l|}{ Sociais } \\
\hline Emprego & 1 & 4 & 2 & $\mathbf{0}$ \\
\hline Part. forneced. & 0 & 5 & 0 & $\mathbf{0}$ \\
\hline \multicolumn{5}{|l|}{ Econômicos } \\
\hline Investimentos & -1 & -1 & 0 & -5 \\
\hline Custo de produção & $\mathbf{0}$ & -3 & -4 & -5 \\
\hline Dem. de divisas & -2 & -4 & -5 & -1 \\
\hline \multicolumn{5}{|l|}{ Energia } \\
\hline Saldo energético & 5 & 3 & 4 & 1 \\
\hline
\end{tabular}

Fonte de dados brutos: Silva Leme (1980).

Obs.: para maiores detalhes, ver nota 3.

$\mathrm{Na}$ oitava fase faz-se a apreciaçá detalhada dos impactos selecionados, classificando-os em bons, indiferentes ou maus. Obviamente, um impacto pode ser bom para um grupo de interesse e mau para outro grupo. Além do mais, a classificação bom mau envolve juízos de valor, o que apresenta dificuldades que devem ser enfrentadas nesta fase ${ }^{3}$. No quadro 6 temos um extrato da apreciação de impactos da AT do Proálcool.

Na nona e última fase é a das conclusóes e recomendaçōes, onde são indicadas as estratégicas mais favoráveis, que modificaçбes devem ser introduzidas nas tecnologias para melhorar seus impactos ou que políticas devem ser usadas para modificar convenientemente os im. pactos. No caso de múltiplos objetivos interdependen tes a serem atingidos, uma técnica que se tem revelado útil na estruturação dos objetivos é o Interpretative Structural Modeling - ISM (Wright, 1980).

\section{GRANDES PROBLEMAS DA APRECIAÇÃO TECNOLOGICA}

A execuçáo de uma apreciaçăo tecnológica não se faz sem grandes problemas. Discutiremos apenas alguns, a saber: os do Patrocinador, equipe, prazo, custo, peculiaridades brasileiras, literatura e recomendaçбes.

Iniciando pelo patrocinador, temos uma segunda peculiaridade brasileira. Nos EUA existem dois grandes patrocinadores, a National Science Foundation (NSF) e - Office of Technology Assessment (OTA), do Congresso Norte-Americano ${ }^{4}$, que juntos patrocinaram, de 1970 a 1974, 40 grandes AT. Nð̃o precisam ser esclarecidos e convencidos sobre a necessidade de AT, pois parte deles a iniciativa de encomendar AT às universidades, instituiçres de pesquisa, ou organizaçóes privadas como os Grupos de Estudos Futuros. No Brasil, entretanto, é necessário convencer ministérios, autarquias, governos estaduais que estão iniciando grandes projetos, do interesse de uma AT. Convencido um patrocinador num caso particular, em novos projetos, problemas ou tecnologias o patrocinador potencial será outro, que deverá ser, inicialmente, conquistado sobre as vantagens da AT.

Prosseguindo com o segundo problema - equipe podemos afirmar que este e o problema crucial da AT. Uma má equipe não produzirá uma boa $\mathrm{AT}$, independen. temente dos recursos de que disponha, de metodologia que obedeça. Convem, pois, discutir os atributos de uma boa equipe. Restringindo-nos aos atributos mais importantes, comentaremos a dimensão, a formação, a interdisciplinaridade e a seleção da equipe.

A experiência, tem demonstrado que equipes menores são mais facilmente coordenáveis. Acredita-se que oito ou nove elementos seja o número máximo de elementos do núcleo central que elabora a AT, sem prejuízo da contratação de consultores para realização de tarefas especializadas, específicas e limitadas. Este número reduzido de elementos do núcleo central torna de grande importância o cuidado em sua formaçáo e o equilibrio na sua composição, que deve possuir representantes das soft-sciences - economia, sociologia, política - e das hard-sciences - engenharia, tecnologia e ecologia. A inclusão de um elemento na equipe pode ser decisiva na orientaçáo que irá ser tomada nos estudos. Assim, por exemplo, se incluirmos na equipe central um especialista em modelos matemáticos, é certo que o estudo acabará tendo vários modelos matemáticos, sendo estes necessários ou não. Nestas condiçðes, antes de se formar a equipe, convém estabelecer-se uma estratégia de trabalho a partir da qual se estabelecerá uma composição ótima.

A equipe deve ser capaz de produzir um trabalho interdisciplinar e não somente multidisciplinar. Multidisciplinar é o trabalho que é uma simples coleção de estudos em disciplinas diferentes. A equipe interdisciplinar é aquela capaz de produzir um trabalho que se situe entre as disciplinas. Para atingir-se a interdisciplinaridade, existem várias recomendaçoes. A primeira é a troca de papéis, fazendo, por exemplo, com que, ocasionalmente, o sociólogo troque o papel com o agrônomo, o engenheiro com o economista etc. A outra 6 reescrever muitas vezes - trabalho, fazendo com que a nova redaça seja feita, preferencialmente, por elementos pertencentes a disciplinas diferentes dos que escreveram a versão anterior, $e$ com que cada versáo seja submetida à revisão do grupo, além da reviāo por consultores e por grupos de interesse. Devem-se vencer os problemas da linguagem, que difere de disciplina para disciplina, e a natural oposiçáo entre os hard-science e os soft-science, os primeiros acostumados a respostas exatas e formulaçбes rigorosas, os últimos familiarizados com problemas sujeitos a maiores incertezas, cuja soluçáo depende de julgamento.

$\mathrm{Na}$ seleçã̃o da equipe é necessário escolher pessoas com características tais como capacidade de aceitar críticas e aptidశ̃o para o pensamento divergente (Taylor, $1975)^{5}$ e não aquelas que estejam, momentaneamente, 
à procura de serviço. Estas últimas, independentemente de sua competência, podem abandonar a AT pelo meio, com prejuízo óbvio para a coordenação do trabalho, e poderão não estar interessadas em permanecer em uma nova $\mathrm{AT}$, impedindo que se forme uma equipe integrada e treinada. E de se notar que a estrutura atual das universidades, e mesmo das instituições de pesquisa, incentiva e premia mais o trabalho situado em cada disciplina e reconhece pouco o trabalho interdisciplinar. Este viltimo fato, se acrescentado ao anterior, de pessoas pouco motivadas para AT, fará com que se constituam equipes instáveis, incapazes de aperfeiçoar-se a longo prazo.

Passando ao problema do prazo, devemos comentar que a seqüência das nove fases descritas anteriormente 6 muito demorada, sendo necessarias formas de encurtar uma AT. Assim, por exemplo, a figura 1 não deve ser considerada um Pert, onde cada fase só pode ser iniciada após o término das fases que a precederam. Interpenetrando as fases, isto $e$, iniciando fases subseqüentes an tes da conclusão das precedentes, tem-se três vantagens. A primeira é reduzir o tempo do estudo: A segunda é ajudar a identificar os resultados da fase anterior, que são críticas para a seguinte. Em terceiro lugar, ajuda a uniformizar a carga do projeto ao longo do tempo para toda a equipe e dentro de cada disciplina.

Outra forma de reduzir o prazo da AT é eliminandose algumas fases. Assim, e possivel trabalhar-se com apenas um cenário ou não se explicitar os grupos de interesse.

Contudo, a melhor forma de limitar o prazo é definir bem as fronteiras do estudo. Quatro aspectos devem ser considerados no estabelecimento dos limites de uma AT: limitação de recursos, limitação cognitiva, centralidade dos subsistemas e fatores políticos (Berg, 1975). Nas limitaçōes dos recursos devemos considerar as restrições de fundos, de tempo e de pessoal. Nas limitaçðes cognitivas, devemos considerar até onde podemos ir dentro da informação que possuímos, da nossa compreensão, da nossa metodologia, sem que as incertezas fiquem tão grandes a ponto de comprometer a credibilidade e a legitimidade do estudo. A centralidade dos subsistemas reflete $o$ julgamento do analista sobre a importância de cada subsistema a ser considerado no resultado da apreciação, em termos de qualidade e quantidade de impactos. Subsistemas considerados pouco centrais não devem ser incluídos no estudo. Os fatores políticos dizem respeito ao objetivo final da AT, que é influir em políticas, modificar ou redistribuir impactos. Para esta finalidade, certas variáveis, certas perspectivas, têm mais relevância do que outras, devendo ser enfatizadas. Note-se que, dos quatro critérios limitativos, os dois primeiros tendem a excluir tópicos e os dois últimos a incluir.

$\mathrm{Na}$ fixação do prazo devemos considerar, finalmente, não ser prudente para os elementos da equipe uma dedicaçáo maior do que meio período de trabalho a uma particular AT, para evitar solução de continuidade de serviço entre dois projetos consecutivos. Juntando todas estas consideraçбes, a experiência mostra que uma AT leva de um a dois anos.

Passando ao problema do custo, vemos que, reunindo os dados anteriores sobre o prazo e tamanho da equipe, acrescentando despesas com consultores e despesas indiretas, teremos sempre um custo elevado. A maioria dos elementos da equipe central deve ser de seniores e os consultores, em geral, stó especialistas muito bem remunerados. A pergunta que surge é o que fazer, quando ñ̃o há tempo ou recursos para fazet uma AT dentro das condiçôes que acabamos de descrever.

A resposta está nas miniapreciações. Estas podem dar uma resposta inicial, menos precisa e mais incompleta do que uma AT completa. Podem ser executadas em um mês ou menos. Também são indicadas, não como um substituto, mas como um complemento das AT completas. Recomenda-se que um estudo completo de AT seja precedido de uma miniapreciação, onde se faça uma interação inicial, rápida, de țoda apreciação, a fim de methor se observarem os problemas e ramificaçðes. Esta primeira interação deve incluir o estudo da base de dados disponíveis, uma lista de impactos por disciplina (econômicos, sociais, ambientais etc.), as inter-relaçōes estruturais entre os setores em estudo, uma redefinição e um aperfeiçoamento da percepção inicial sobre as grandes questðes.

Passando ao problema das peculiaridades brasileiras na realização de uma $\mathrm{AT}$, temos, além das já citadas, como in ício dos estudos após a tecnologia ou proje to ter-se tomado um fato irreversível e dificuldade na obtenção de patrocinador, também problemas culturais e a disponibilidade de dados. A AT nasceu nos EUA, espalhou-se pelos países desenvolvidos, mas guarda em seus métodos traços de sua cultura de origem, $o$ que traz dificuldades para sua adaptação no Brasil. Um exemplo singelo desta dificuldade é o pequeno respeito do brasileiro pelo correio, que dificulta a coleta de informaçōes; um exemplo mais sério e a diferença de atitude entre norte-americano e brasileiro no que diz respeito à previsão do futuro. O norte-americano se preocupa muito mais em prever e planejar o futuro do que o brasileiro. Nos EUA, a estabilidade política, econômica e social dá maiores benefícios para uma mentalidade orientada para o futuro. A inflação e as repetidas mudanças das regras do jogo polrtico fazem com que pensar no futuro e planejar sejam de menor interesse no Brasil. Nestas condiçбes, nos Delphi, em que vamos colher a imagem do futuro de uma amostra de pesquisadores nos EUA, colheremos uma imagem mais meditada do que no Brasil. E possível, mesmo, que o respondente do Delphi, no Brasil, esteja imaginando pela primeira vez o futuro, no que diz respeito a algumas perguntas do questionário no instante de respondêto. Poderemos minorar os efeitos negativos deste problema preparando os Delphi com maior cuidado, encadeando perguntas que guiem o raciocínio do respondente, garantindo, assim, que as respostas não sejam simples "chutes".

Outra peculiaridade do Brasil, digna de menção, é a falta de dados. Durante a realização do trabalho, um problema que surge é o de optar entre técnicas simples e sofisticadas, tais como, entre as últimas, a Cross Impact Analysis, o emprego de análogos aos jogos de empresa na construção de cenários, 0 uso de diversas ferramentas de pesquisa operacional. Dada a qualidade e quantidade de informação existente no Brasil, julgamos interessante preferir sempre as técnicas mais simples.

Passando ao problema da literatura, desejamos mencionar que, sem embargo da grande utilidade dos livros de teoria de AT (ver, por exemplo, Arnstein \& Christakis, 1975), e de grande importância na realização do trabalho 
a consulta de relatórios de AT já executadas (por exemplo, as AT listadas na NTIS - 1976 e 1977 - e, entre nós, CNPq - 1978 - e Planalsucar e outros - 1981). As soluçðes que encontramos nos relatórios são muitas vezes mais práticas que as recomendadas nos livros de teoria.

Finalizando com o problema das recomendações, temos que este é um dos pontos mais controvertidos de uma AT. Existe uma corrente que defende que, nas recomendaçð̃es, o estudo "advogue uma política", versus outra que defende que o estudo "apresente imparcialmente opções de políticas". Devemos, inicialmente, comentar que a segunda escolha é mais difícil do que a primeira. $O$ grupo, quer queira, quer não queira, ao longo do trabalho formou sua opinião e, de uma forma inconsciente, a transmitirá nas recomendações. Também é difícil que o grupo seja neutro com relação à opinião do patrocinador. Ambas as escolas têm seus defensores, sendo mais numerosos os que defendem a "apresentação imparcial de opçðes".

Ainda a respeito das recomendaçðes, desejamos encarecer a importância do sumário executivo. Este é um capítulo que acompanha o estudo, que complementa a leitura do mesmo, mas que é auto-suficiente, podendo ser lido separadamente do resto do trabalho por aqueles que têm pouco tempo, entre os quais, normalmente, estão os executivos tomadores de decisões. Não tem uma extensão prefixada, de duas até 30 páginas, nem um conteúdo rígido. Inclui, obrigatoriamente, um resumo do trabalho e as recomendaçð̃es, podendo conter também as conclusōes, as questões suscitadas, síntese da metodologia, uma visão global etc. Um sumário executivo facilita o conhecimento do trabalho, fazendo com que um nú. mero maior de pessoas tome conhecimento do mesmo. Ora, muitos afirmam que a medida do sucesso de uma AT é o número de seus leitores e as discussóes que suscitar. O sumário executivo, indubitavelmente, concorrerá para esta meta.

\footnotetext{
* O presente trabalho foi realizado, sob os auspícios do Gonvênio n? 81-07-428, celebrado entre o CNPq e a USP, como material para os cursos de política cientffica e tecnológica.

1 Delphi é uma forma elaborada de questionário, no qual conseguimos estabelecer uma discussāo entre elementos de um grupo de especialistas que não estāo em contato entre si, objetivando-se uma convergência de opiniāo. Apresenta vantagens sobre reuniōes, tais como menor custo - no caso de os especialistas estarem espalhados geograficamente - eliminação dos vieses provocados pelos efeitos status e persuasão. Pode ser aplicado tanto na previsão do estado da sociedade, quanto na previsăo tecnologica, especialmente nos atribuios quantificáveis.

2 Trend Impact Analysis é uma forma de se fazerem extrapolações, onde se combina a simples extrapolação matemática com mudanças de tendências associadas a probabilidades, introduzidas pela equipe.
}

3 Uma forma simples de ser executada a apreciaçăo é empregando uma matriz onde as estratégias sāo linhas, os impactos colunas e notas são atribuldas a cada célula. A magnitude da nota representa a importância do impacto e seu sinal, se é bom ou mau. Devem-se constituir matrizes diferentes para os diversos grupos de interesse e verificar a sensibilidade das notas às mudanças de cenários. Obviamen te, todo o processo se aplica aos impactos que dependem da estratégia.

4 O OTA é um braço analítico e de alerta do Congresso norteamericano, patrocinando AT em todos os campos, como uma forma de o Legislativo melhor controlar as iniciativas do Executivo.

5 Pensamento divergente é o emprego na solução de problemas mal definidos, contrapondo-se ao pensamento convergente, empregado na solução de problemas bem definidos. Enquanto os problemas bem definidos se caracterizam por ter uma resposta certa, sendo possível ser específico sobre o que deve ser realizađo e as pessoas necessárias na sua solução, os problemas mal definidos admitem várias respostas, sendo indefinido o que seja um resultado ćtimo ou os passos necessários para atingi-lo. Os problemas da "ciência normal", no sentido de Kuhn (1970), pertence à primeira categoria, ao passo que como se ganha uma partida de xadrez ou como se estabelece a fronteira de uma AT são problemas mal definidos.

\section{REFERENCIAS BIBLIOGRÁFICAS}

Almeida, H.S. Um estudo de vínculo tecnológico entre: pesquisa, engenharia, fabricaçāo e consumo. Tese apresentada à Escola Politécnica da USP. São Paulo, 1981.

Arnstein, S.R. \& Christakis, N.R. Perspectives on technology assessment. Columbus, Ohio, Academy for Contemporary Problems, 1975.

Berg, M.R. Methodology. In: Arnstein, S.R. \& Cinristakis, N.R. Perspectives on technology assessment. Columbus, Ohio, Academy for Contemporary Problem, 1975. p. 63-72.

Bright, J.R. A brief introduction to technology forecasting concepts and exercises. Austin, Texas, The Peguamid Press, 1972.

CNPq. Avaliação tecnológica do álcool etılico. Brasilia, dez. 1978.

Coates, J.F. The identification and selection of priorities for technology assessment. Feb. 1974.

—. Technology assessment at N.S.F. In: Amstein, S.R. \& Christakis, N.R. Perspectives on technology assessment. Columbus, Ohio, Academy for Contemporary Problems, 1975. p. 11-7. 
Futures Group. A technology assessment of geothermal energy resounce development. Glastenbury, Connecticut, 1975.

Trend Impact Analysis. Glastenbury, Connecticut, s.d. mimeogr.

Kuhn, T. The structure of scientific revolution. Chicago, University of Chicago Press, 1970.

Mic. Ministry of Industry and Commerce. Assessment of Brazil's National Alcohol Program. Brasilia, 1981.

Neilson, W.A. et alii. Webster's New International Dictionary of English Language. Springfield, Mass., Merriam, 1939.

NTIS. National Technical Information Service. Technological A ssessment. v. 1.1964 - June 1975. A bibliography with abstracts. Springfield, U.S. Department of Commerce, 1976.
Technological assessment. v. 2. July 1975 - July 1977. A bibliography with abstracts. Springfield, Virginia, U.S. Departament of Commerce, 1977.

Planalsucar; Instituto de Administraçăo/USP \& Instituto Mauá de Tecnologia. Previsāo e análise tecnológica do Proálcool. out. 1981. mimeogr.

Silva Leme, R.A. Technology assessment of Proálcool. Proceedings of the IV International Symposium on Alcohol Fuels Technology. Oct. 1980. v. 2. p. 861-7.

Taylor, J.B. Building an interdisciplinary team. In: Arnstein, S.R. \& Christakis, N.R. Perspectives on technology assessment. Columbus, Ohio, Academy for Contemporary Problems, 1975. p. 45-60.

Wrigth, J.T. Análise e estrutunafão de modelos; uma metodologia para lidar com complexidade. São Paulo, Faculdade de Economia e Administração da USP, 1980. mimeogr.

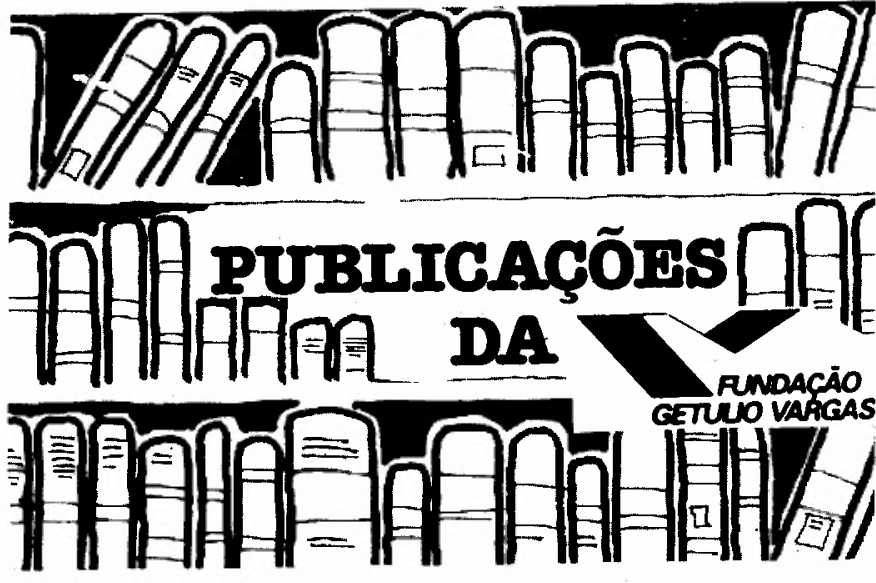

ADMINISTRAÇATO DA PRODUÇAOO

Manual de administração da produçāo - vol. 1 Claude Machline, Ivan de Sá Motta \& outros 7. a edição - 1984 - Cr\$20.000

Manual de administraçâo da produção - vol. 2 Claude Machline, Ivan de Sa Motta \& outros 5. ediçấo - 1982 - Cr\$ 17.900

A segmentação como alternativa estratégica em empresas brasileiras

Raimar Richers

$1 .{ }^{\mathrm{a}}$ edição - Cr\$ 3.300

\section{ADMINISTRAÇĀO DE EMPRESAS}

Administração de projetos culturais - três experiências FGV/EIAP

$1 .^{\mathrm{a}}$ edição $-1982-\mathrm{Cr} \$ 7.200$

Administração e contexto brasileiro

Alberto Guerreiro Ramos

2. ediçâo - 1983 - Cr\$ 15.500
Administração e gerência - do artesanato à automaçāo

Cesar Cantanhede

2. a ediçāo - 1983 - Cr\$7.500

Análise de projetos de investimento

Paulo Henrique Soto Costa \& Eduardo V. Attie

$1 .^{a}$ edição -1984 - Cr\$ 11.300

Análise estatística e processo decisório

Willian S. Peters \& George W. Summers

2. ediçâo - 1978 - Cr\$ 10.500

Comportamento administrativo - estudo dos processos

decisórios nas organizaçōes administrativas

Herbert A. Simon

3. a edição - 1979 - Cr\$ 10.500

O comportamento humano na empresa - uma antologia Yollanda Ferreira Balcäo \& Laerte Leite Cordeiro

$4 .^{\mathrm{a}}$ edição -1979 - Cr\$16.200

Atençðo: Preços Wlidos so at6 30.6.85

\section{LURARIAS DA FGV}

Rio de Janeiro

Livraria J. Carneiro Felipe - Praia de Botafogo, 188

Tels.: $551-1542$ - Ramal 353 ou $551-0698$

Livraria Teixeira de Freitas - Av. Presidente Wilson, 228-A Tel.: 262-11169

São Paulo

Livraria Prefeito Faria Lima - Av. 9 de Julho, 2029

Tel.:284-2311

Brasilia

Livraria de Brasilia - Setor Comercial Local Sul - 104

Bloco A, Loja 37 - Tel.: 224-6128 